\title{
Hypersensitivity pneumonitis associated with co-proxamol (paracetamol + dextropropoxyphene) therapy
}

\author{
S P Matusiewicz, W A H Wallace, G K Crompton
}

\begin{abstract}
Summary
A 61-year-old man developed hypersensitivity pneumonitis and skin rash in close association with taking co-proxamol. These problems occurred in spite of being treated with prednisolone $40 \mathrm{mg}$ daily (20 $\mathrm{mg}$ daily at the time of presentation) for assumed cranial arteritis. A therapeutic challenge with paracetamol was negative and the patient continues to take this drug. It seems likely that this patient's rash and hypersensitivity pneumonitis was caused by dextropropoxyphene. Dextropropoxyphene has not been reported previously as a cause of hypersensitivity pneumonitis.
\end{abstract}

Keywords: adverse drug reaction; hypersensitivity pneumonitis; co-proxamol; dextropropoxyphene

Hypersensitivity pneumonitis is known to be caused by a large number of drugs, although it is more often associated with inhaled protein antigens. Co-proxamol, a combined preparation containing paracetamol and dextropropoxyphene, is a widely used analgesic and is well tolerated in recommended doses. Skin rash has been associated with its use ${ }^{1}$ and two cases of paracetamol pneumonitis have been reported $^{2} 3$ but pulmonary complications of dextropropoxyphene have not been reported either in the literature or to the Committee on Safety of Medicines.

\section{Case report}

A 61-year-old man presented with a 2-month history of increasing breathlessness. He had stopped smoking 13 years previously because of cough, and for some years had been troubled with headache which had responded to corticosteroid therapy and a presumed diagnosis of cranial arteritis was made in 1988. Prednisolone therapy was withdrawn in 1992, but headaches recurred in early 1993. Prednisolone was restarted in a dose of $40 \mathrm{mg}$ daily with only partial response and co-proxamol was taken as required to relieve headache. $\mathrm{He}$ then developed breathlessness which progressed steadily over a 2-month period. There was no exposure to any known causes of extrinsic allergic alveolitis and his only drug therapy was co-proxamol and prednisolone, the dose of which had been reduced to $20 \mathrm{mg}$ daily. On examination there were bilateral lateinspiratory basal crackles audible. A chest $\mathrm{X}$-ray had a vague shadowing in both lower zones suggesting an interstitial abnormality. An $\mathrm{FEV}_{1}$ of 2.6 (predicted $3.4 \pm 0.5 \mathrm{l}$ ) and an FVC of 4.1 (predicted $4.2 \pm 0.71$ ), together with the lung volumes and transfer coefficient (see table), suggested a combined obstructive and restrictive defect. Electrocardiogram and echocardiography were normal. Haematological indices, urea, electrolytes and standard liver function tests were normal, but there was an elevation of lactate dehydrogenase $(\mathrm{LDH})$ of $531 \mathrm{IU} / 1$ (normal range 92-395). Serum was negative for Aspergillus fumigatus and avian precipitins and autoantibodies. Arterial blood gas analysis revealed mild hypoxaemia: $\mathrm{PaO}_{2} 8.9$ $\mathrm{kPa}, \mathrm{PaCO}_{2} 5.9 \mathrm{kPa}$, hydrogen ion $36.8 \mathrm{nmol} / 1$. A ventilation/perfusion scan was normal. Exercise induced $\mathrm{O}_{2}$ desaturation to $88 \%$ at $1.5 \mathrm{~min}$ at 40 watts.

It was concluded that this man had some form of interstitial lung disease which had developed while being treated with prednisolone (20-40 $\mathrm{mg}$ daily) for presumed cranial arteritis. A video-assisted thoracoscopic lung biopsy was performed.

\section{PATHOLOGY}

The biopsy taken from the left lower lobe measured $4.5 \times 3 \times 1.5 \mathrm{~cm}$ and had a normal macroscopic appearance. Histological examination showed the presence of a focal

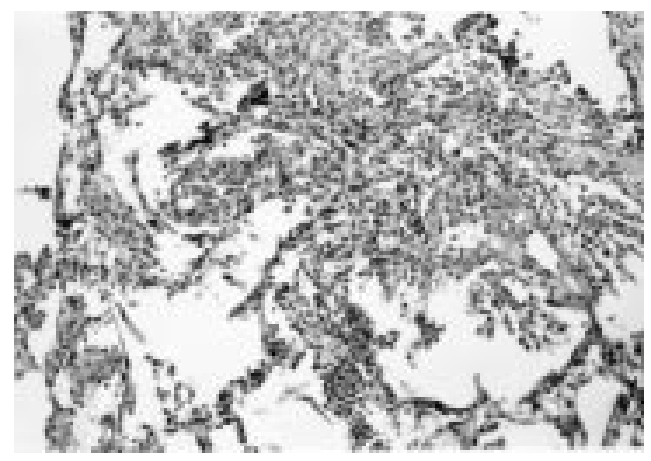

Figure Photomicrograph of the lung biopsy showing a focus of interstitial pneumonitis composed of lymphocytes and macrophages with occasional eosinophils. Small plugs of organising intraluminal exudate are present and inflammatory cells are identified within the air spaces but there is little evidence of interstitial scarring (original magnification $\times 100$ ) 
Table Serial pulmonary function test results showing a marked improvement in vital capacity (VC) and total lung capacity (TLC) from the initial baseline levels after stopping co-proxamol therapy. Little change in carbon monoxide transfer factor $\left(\mathrm{K}_{\mathrm{co}}\right)$ was, however, seen

\begin{tabular}{llll}
\hline Date & TLC (l) & $V C(l)$ & $K_{C O}(\mathrm{mmol} / \mathrm{min} / \mathrm{kPa} / \mathrm{l})$ \\
\hline 13 May 93 & 5.70 & 4.30 & 1.05 \\
06 Sep 93 & 5.15 & 3.75 & 0.96 \\
08 Nov 93 & 5.60 & 3.95 & 0.86 \\
17 Jan 94 & 6.15 & 4.05 & 1.03 \\
26 Jan 95 & 6.85 & 5.30 & 1.05 \\
Predicted & $6.3 \pm 0.8$ & $4.2 \pm 0.7$ & $1.42 \pm 0.27$ \\
\hline
\end{tabular}

interstitial pneumonitis composed of lymphocytes, macrophages and occasional eosinophils (figure). Focally, this was also associated with evidence of an organising fibrinous exudate.

Granulomata were not identified. The inflammatory lesions had a predominantly centri-acinar distribution and were not associated with any significant degree of interstitial fibrosis. These histological appearances suggested a diagnosis of hypersensitivity pneumonitis. ${ }^{4}$

PROGRESS

Following the lung biopsy, co-proxamol was taken, mainly for chest pain, and breathlessness became more troublesome. A diffuse skin rash then developed. Co-proxamol was stopped and the rash disappeared within a few days and breathlessness improved. Co-proxamol was then reintroduced as a challenge and the rash recurred and breathlessness deteriorated again within a few hours of the first dose. Subsequently, a challenge with paracetamol caused no pulmonary or systemic reaction and this drug was continued as required for headache. The dose of prednisolone has been gradually reduced to $2 \mathrm{mg}$ daily and the patient is now free from symptoms, except for occasional headache. Pulmonary function has also improved (table), the total lung capacity having increased by over one litre, and the serum $\mathrm{LDH}$ returned to normal. ${ }^{5}$

\section{Discussion}

This 61-year-old man developed hypersensitivity pneumonitis and skin rash in close association with taking co-proxamol. These problems occurred in spite of being treated with prednisolone in an initial dose of $40 \mathrm{mg}(20 \mathrm{mg}$ daily at the time of presentation) for assumed

1 ABPI Data Sheet Compendium 1998-9. London: Datapharm Publications Limited, 1998.

2 Kitaguchi S, Miyazawa T, Minesita M, Doi M, Takahashi K, Yamakido M. A case of acetaminophen-induced pneumonitis (Japanese). Nippon Kyobu Shikkan Gakkai Zassh 992;30:1322-6.

3 Kudeken N, Kawakami K, Kakazu T, et al. A case of acetaminophen-induced pneumonitis (Japanese). Nippon Kyobu Shikkan Gakkai Zasshi 1993;31:1985-90.

\section{Learning points}

- co-proxamol (paracetamol + dextropropoxyphene) may cause a hypersensitivity pneumonitis, a reaction not previously reported

- drugs are an important aetiological consideration in patients presenting with diffuse interstitial lung disease

- recognition of drug-induced hypersensitivity pulmonary reactions is important as the effects may be in part reversible before extensive pulmonary fibrosis occurs

- thoracoscopic lung biopsy is an important investigation in patients with diffuse interstitial lung disease where the nature of this is unclear

cranial arteritis. The diagnosis of cranial arteritis was not confirmed histologically, and seems unlikely, since the patient has remained well for almost 4 years while taking prednisolone in a small dose of $2 \mathrm{mg}$ daily. A therapeutic challenge with paracetamol was negative and the patient continues to take this drug occasionally. A therapeutic challenge with dextropropoxyphene was considered too dangerous to perform, since the pulmonary problem developed when the patient was taking a large dose of prednisolone (30-40 mg daily) and the rash broke through treatment with this drug in a dose of $20 \mathrm{mg}$ daily. It does, however, seem likely that both the rash and the hypersensitivity pneumonitis were caused by dextropropoxyphene. There was no evidence of an autoimmune disorder. The pulmonary symptoms developed many weeks after prednisolone was initially prescribed and then subsided after dextropropoxyphene was withdrawn and corticosteroid therapy reduced. This makes any other cause of the rash and the pneumonitis unlikely. Unfortunately, pulmonary function tests were not performed immediately before and after the challenge with co-proxamol, which caused recurrence of the skin rash and an increase in breathlessness. This challenge was performed in the patient's home and was supervised by his general practitioner.

We believe that this is the first reported case of dextropropoxyphene as a cause of hypersensitivity pneumonitis. We believe that pathologists and chest physicians encountering patients with an histological diagnosis of hypersensitivity pneumonitis should be aware of the possibility that this might represent a drug effect.

4 Hammer SP. EAA - histiocytosis X. In: Dail DH, Hammer SP, eds, Pulmonary pathology. New York: Springer Verlag, 1988; pp 379-416.

5 Matusiewicz SP, Williamson IJ, Sime PJ, et al. Plasma lactate dehydrogenase: a marker of disease activity in cryptogenic fibrosing aveolitis and extrinsic allergic alveolitis. Eur Respir f 1993;6:1282-6. 


\title{
Reversible cerebellar involvement in the idiopathic hypereosinophilic syndrome
}

\author{
Fernando Díaz, Julio Collazos
}

\begin{abstract}
Summary
We report a patient with cerebellar manifestations due to the idiopathic hypereosinophilic syndrome, in whom magnetic resonance imaging (MRI) showed hyperintense lesions in both cerebellar hemispheres. Following steroids and hydroxyurea administration, the lesions on MRI disappeared, suggesting that the pathogenetic mechanism was reversible and did not cause significant structural damage. To our knowledge, the resolution of the abnormal MRI findings have not been reported to date in the idiopathic hypereosinophilic syndrome.
\end{abstract}

Keywords: hypereosinophilic syndrome; cerebellum; magnetic resonance imaging; hydroxyurea

The idiopathic hypereosinophilic syndrome (HES) is an uncommon chronic disease of unknown aetiology characterised by a sustained overproduction of eosinophils that results in infiltration of multiple tissues. HES may result from eosinophilic differentiation of a clone of neoplastic cells or from reactive eosinophilia. In other patients, however, HES is idiopathic, ${ }^{1}$ although this condition may include different diseases. ${ }^{2}$ Any organ system may be involved in idiopathic HES, the heart and the nervous system being the organs most commonly implicated. ${ }^{3}$ Three types of neurologic manifestations have been described in this syndrome: encephalopathy, peripheral neuropathy, and focal central nervous system deficits from emboli or haemorrhage. ${ }^{4}$ We report a patient with cerebellar manifestations and abnormal findings on magnetic resonance imaging (MRI), both of which reverted with therapy.

\section{Case report}

A 65-year-old woman was admitted to our hospital because of a 3-month history of recurrent dizziness, asthenia, and malaise. She had osteoarthritis of the knee and cervical spine without other relevant medical history. On admission, both neurological and general physical examination were normal. White blood cell count was $34.2 \times 10^{9} / 1,54 \%$ eosinophils, including eosinophilic myeloid precursors, 28\% neutrophils, $11 \%$ lymphocytes, and $7 \%$ band forms, haemoglobin $137 \mathrm{~g} / \mathrm{l}$, platelet count $283 \times 10^{9} / 1$, and erythrocyte sedimentation rate $25 \mathrm{~mm} / \mathrm{h}$ (normal less

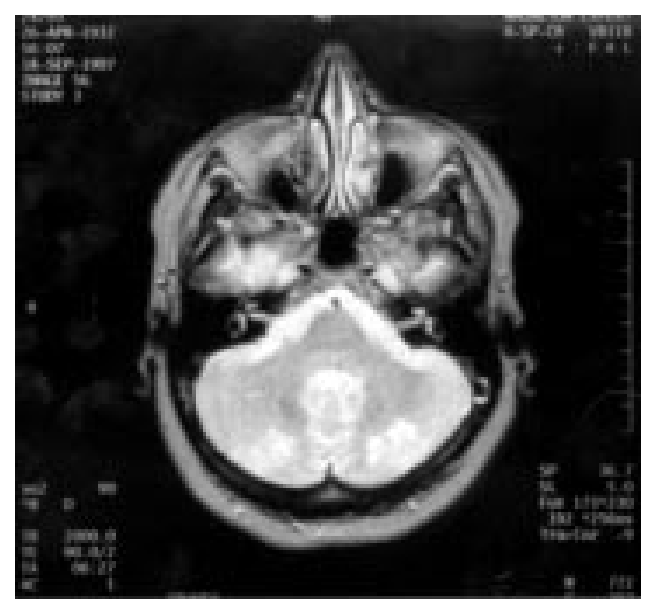

Figure 1 T2-weighted MRI showing hyperintense lesions in both cerebellar hemispheres

than 20). Routine chemical tests were normal except for alkaline phosphatase $555 \mathrm{U} / 1$ (98-279), gamma glutamyl transpeptidase 245 $\mathrm{U} / 1$ (11-50), and alanine aminotransferase 82 $\mathrm{U} / 1$ (1-40). Serum vitamin B12 level was 1096 $\mathrm{pmol} / 1$ (174-713), and IgE level $260 \mathrm{IU} / \mathrm{ml}$ (less than 100). Antinuclear antibodies, rheumatoid factor, and antineutrophil cytoplasmic antibodies were negative. Alpha-fetoprotein, carcinoembryonic antigen, CA 19-9, and human chorionic gonadotropin were within normal limits. Several stool examinations for parasites were negative. Serologic tests for Brucella, Mycoplasma, Chlamydia, Toxoplasma, Q fever, syphilis, echinococcosis, fascioliasis, trichinosis, cytomegalovirus, and hepatitis $\mathrm{B}$ and $\mathrm{C}$ virus were negative. Chest radiographs and thoracic, abdominal and pelvic computed tomography (CT) were normal. A biopsy of bone marrow demonstrated marked eosinophilia (28\%) with a shift to the left in eosinophil maturation. Liver biopsy revealed steatosis, portal tracts infiltrated by eosinophils that expanded into the parenchyma, and isolated hepatic cell necrosis.

On the 14th hospital day, the patient developed an unstable gait and ataxia of the left limbs. A cerebral CT was normal and a lumbar puncture yielded clear cerebrospinal fluid. Its analysis revealed 3 leukocytes $/ \mathrm{mm}^{3}$, protein $0.30 \mathrm{~g} / 1$ (normal less than 0.4 ), glucose 3.8 $\mathrm{mmol} / \mathrm{l}$ (2.8-4.4), and normal cytological study and negative cultures. However, MRI showed hyperintense, vascular type lesions on T2-weighted images in both cerebellar hemi- 
Figure 2 MRI after 2 months of therapy showing almost complete resolution of the cerebellar lesions

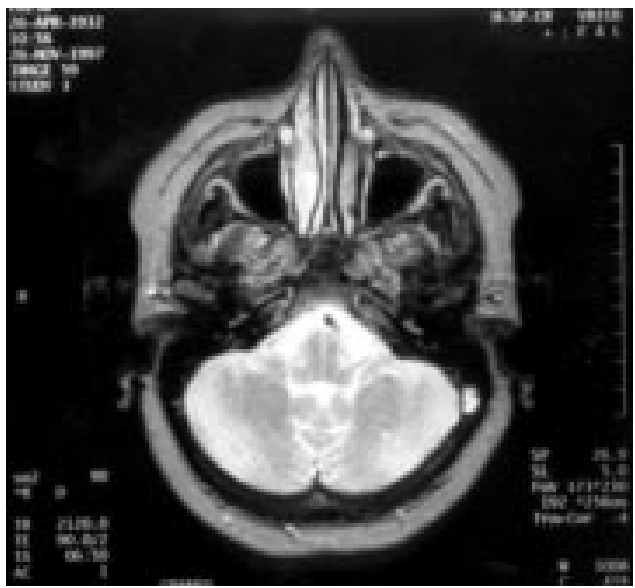

spheres, although they were more marked in the left hemisphere (figure 1). A transthoracic echocardiography was normal, ruling out intracardiac thrombi.

A diagnosis of idiopathic HES was made, and treatment was started with prednisone, 1 $\mathrm{mg} / \mathrm{kg} /$ day, and aspirin $200 \mathrm{mg} /$ day. However, eosinophilia and neurologic manifestations persisted and 8 days later, hydroxyurea, 1500 mg daily, was added. This was followed by a clear improvement within the next few days. The patient was discharged on tapering doses of prednisone, which were withheld one month later, and hydroxyurea and aspirin. Two months later, the patient was asymptomatic with a maintenance dose of hydroxyurea of $1000 \mathrm{mg} /$ day, and another MRI revealed that the hyperintense cerebellar lesions had practically resolved (figure 2). Serum levels of vitamin B12 and IgE were normal and white blood cell count was $6.3 \times 10^{9} / 1$, only $5 \%$ of which were eosinophils.

\section{Discussion}

Idiopathic HES is characterised by sustained eosinophilia and organ system damage. This overproduction of eosinophils might be caused by dysregulated production of eosinophilopoietic cytokines by T-lymphocyte clones. ${ }^{25}$ The pathogenetic mechanisms of this disease are not known, although granular substances produced by eosinophils may play a role in the tissue injury. ${ }^{235}$ In fact, the eosinophils of these patients have an increased propensity to release their granule proteins. ${ }^{6}$

As mentioned above, involvement of the nervous system may take the form of focal deficits due to emboli or haemorrhage, generalised encephalopathy, and peripheral neuropathy. Peripheral neuropathy is the most common neurologic dysfunction. Different types of neuropathy are seen in HES, including symmetric or asymmetric sensory polyneuropathy, mononeuritis multiplex, radiculopathy and muscle atrophy due to denervation. Nerve biopsy usually shows an axonal neuropathy. Nevertheless, in a few cases, vasculitis

\section{Summary points}

idiopathic HES is an uncommon disease characterised by sustained eosinophilia and organ system damage

- the nervous system is commonly involved, but neurological complications may be reversible with early therapy

- treatment should be initiated as soon as HES is diagnosed order to avoid a permanent lesion

may be seen. ${ }^{2}$ Encephalopathy is characterised by memory loss, altered behaviour, confusion, ataxia and upper motor neurone signs with increased muscle tone, hyperreflexia and a positive Babinski sign. Strokes or transient ischaemic episodes may be caused by thromboemboli originated in the heart. ${ }^{4}$ However, thrombo-emboli may also occur without cardiac disease demonstrable by echocardiography. ${ }^{2}$ In addition, local intravascular thrombosis might take place within the vessels of the nervous system, although this mechanism has not been confirmed. ${ }^{2}$ Interestingly, an endothelial lesion, as a consequence of direct damage from infiltration of eosinophils, and the release of eosinophil-derived neurotoxin and eosinophil cationic protein, have been suggested as pathogenetic mechanisms of encephalopathy, peripheral neuropathy and cardiopathy. ${ }^{34}$ The present case supports this mechanism because no evidence of intracardiac thrombi was found and both clinical manifestations and MRI findings quickly resolved after the onset of effective antieosinophilic therapy.

The treatment of patients with idiopathic HES and organ involvement consists of prednisone. However, cytotoxic agents should be added if the patient does not respond to steroids. ${ }^{3}$ Cytotoxic chemotherapy is used in order to lower the eosinophils count, given its potential capacity of tissular injury, although some manifestations of HES do not appear to correlate with the levels of eosinophils. ${ }^{23}$ Hydroxyurea is the most common cytotoxic agent employed in HES. Its primary site of action is the ribonucleotide diphosphate reductase, which inhibits the formation of all marrow-derived cells. ${ }^{2}$ Other treatment modalities have been used in patients in whom eosinophilia is refractory to conventional therapy. ${ }^{7}$ Patients with neurological complications are more likely to be resistant to prednisone. ${ }^{2}$ Our patient did not respond to steroid treatment and showed a remarkable clinical, analytical and radiologic improvement after hydroxyurea was started. To our knowledge, such a clear response, with MRI demonstration of the resolution of the lesions, has not been reported to date. This case suggests that anti-eosinophilic therapy should be initiated without delay once a diagnosis of HES is made in order to avoid permanent, structural damage. 
1 Bain BJ. Eosinophilic leukaemias and the idiopathic hypereosinophilic syndrome. Br 7 Haematol 1996;95:2-9.

2 Weller PF, Bubley. The idiopathic hypereosinophilic syndrome. Blood 1994;83:2759-79.

3 Fauci AS, Harley JB, Roberts WC, Ferrans VC, Gralnick HR, Bjornson BH. The idiopathic hypereosinophilic yndrome. Ann Intern Med 1982;97:78-92

4 Moore PM, Harley JB, Fauci AS. Neurologic dysfunction in the idiopathic hypereosinophilic syndrome. Ann Intern Med 1985;102:109-14.

5 Liesveld JL, Abboud CN. State of the art: the idiopathic hypereosinophilic syndromes. Blood Rev 1991;5:29-37.
6 Carlson M, Oberg G, Peterson C, Venge P. Releasability of human hypereosinophilic eosinophils is related to the human hypereosinophilic eosinophils is related
density of the cells. Br f Haematol 1994;86:41-7.

density of the cells. Br F Haematol 1994;86:41-7.
Butterfield JH, Gleich GJ. Interferon-alpha treatment of six patients with the idiopathic hypereosinophilic syndrome. Ann Intern Med 1994;121:648-53.

8 Smit AJ, van Essen LH, de Vries EG. Successful long-term control of idiopathic hypereosinophilic syndrome with etoposide. Cancer 1991;67:2826-7.

\section{A patient with fever and an abdominal aortic aneurysm}

Gavin D Barlow, Stephen T Green

\begin{abstract}
Summary
A 55-year-old man with an abdominal aortic aneurysm presented with fever and abdominal pain 3 weeks after an episode of Salmonella gastroenteritis. His symptoms persisted despite antimicrobial therapy. Two abdominal computed tomography (CT) scans showed no evidence of aortitis. His abdominal pain worsened and further investigation including a third CT scan demonstrated a leaking aortic aneurysm. The wall of the aorta was shown to contain Gram-negative bacilli. This case illustrates the difficulty in diagnosing bacterial aortitis.
\end{abstract}

Keywords: Salmonella; aortitis

Patients with aortic aneurysms are at increased risk of bacterial aortitis, Salmonellae being the commonest cause. ${ }^{1}$ The diagnosis can be difficult and a high index of suspicion is required on the part of the physician. We describe a case of Salmonella aortitis in a patient with a pre-existing aortic aneurysm. Despite a delayed diagnosis, the patient made a full recovery following aortic repair and antimicrobial therapy.

\section{Case report}

A 55-year-old man presented to a general surgical unit with a 3-day history of general malaise, fever and right iliac fossa pain. He had developed watery diarrhoea 3 weeks earlier and faecal culture had grown Salmonella typhimurium phage type 208 sensitive to ampicillin, ciprofloxacin, trimethroprim and gentamicin, but resistant to cefuroxime. He was managed conservatively by his general practitioner with resolution of symptoms prior to admission. His medical history included long-standing hypertension, an anterior myocardial infarction and quadruple coronary artery bypass grafting 6 and 8 years earlier, respectively, renal colic and a $5-\mathrm{cm}$ diameter infrarenal abdominal aortic aneurysm. The latter had been diagnosed inci- dentally the year before during a hospital admission for pneumonia and an elective repair of this aneurysm had been cancelled when he was found to have poor left ventricular function. His medications were aspirin, diltiazem, enalapril, isosorbide mononitrate, frusemide and omeprazole. On examination his temperature was $38^{\circ} \mathrm{C}$. Chest auscultation was normal and abdominal palpation revealed a tender but soft right iliac fossa and a nontender aortic aneurysm. Initial investigation showed a haemoglobin of $11.0 \mathrm{~g} / \mathrm{dl}$, a white cell count of $8.5 \times 10^{9} / 1$ with a normal differential, a C-reactive protein of $168 \mathrm{mg} / \mathrm{l}$ and an amylase of $77 \mathrm{IU} / 1$. A chest X-ray showed right basal atelectasis and an abdominal ultrasound scan revealed a $5-\mathrm{cm}$ diameter infrarenal aortic aneurysm. Echocardiography showed no evidence of endocarditis. Microbiological analysis of blood, sputum, faeces and urine were negative. He was initially commenced on intravenous cefuroxime $750 \mathrm{mg}$ and metronidazole $500 \mathrm{mg}$, both tid.

On day 2 he became hypotensive with a blood pressure of $70 / 40 \mathrm{mmHg}$. A central venous line was inserted for fluid management and he was commenced on intravenous ciprofloxacin 400 mg bid. Abdominal computed tomography (CT) scans on days 2 and 5 showed no evidence of either a change in size or leakage from the

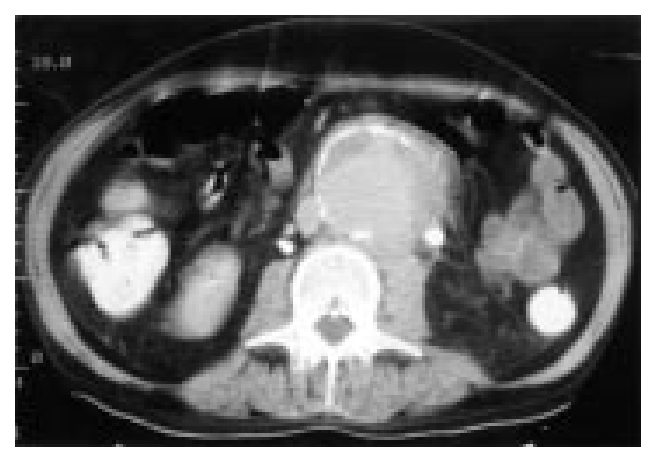

Figure Abdominal CT scan showing a leaking aortic aneurysm with retroperitoneal extension 
aneurysm but did identify small bilateral pleural effusions and renal calculi. Despite continuing antimicrobial therapy he remained unwell with general malaise, and intermittent pyrexia and he developed severe left loin and iliac fossa pain. On day 13 he was transferred to the regional infectious disease unit where a bone scan showed isotope retention in the left ureter. Intravenous urography showed bilateral renal calculi and delayed emptying of the left ureter, and an abdominal CT scan confirmed an $8.5-\mathrm{cm}$ diameter leaking aortic aneurysm with retroperitoneal extension causing compression of the left ureter (figure). Aortic aneurysm repair was performed using a straight celsoft/ rifampicin graft. At operation the aorta and surrounding tissues were inflamed, oedematous and friable. Microscopy of the aortic wall revealed the presence of Gram-negative bacilli, although bacterial culture was negative. He was discharged home 27 days after admission. Oral ciprofloxacin $500 \mathrm{mg}$ bid was continued for one month after discharge and at out-patient reviews since there has been no evidence of persistent infection. The clinical findings were consistent with a diagnosis of Salmonella aortitis.

\section{Discussion}

Salmonella species are the commonest cause of bacterial aortitis accounting for one third of all cases. ${ }^{1}$ This reflects the incidence of Salmonella infection in the community, ${ }^{2}$ the fact that $3-8 \%$ of Salmonella infections result in bacteraemia, ${ }^{34}$ and the predilection of Salmonellae to infect damaged tissues such as atherosclerotic vascular endothelium. ${ }^{5}$ Patients are usually male, over 50 years old and may present in a variety of ways ranging from the typical features of a rupturing aortic aneurysm to pyrexia of unknown origin. There is often no history of gastroenteritis and back or abdominal pain in a patient with fever appears to be the most consistent feature.$^{67} \mathrm{~A}$ pulsatile abdominal mass is palpable in only $42 \%$ of cases. ${ }^{7}$ In insidious presentations a high index of suspicion in the supervising physician is arguably the most important factor in making the diagnosis, which can be confirmed in most cases by CT scanning. ${ }^{8}$ As in our patient, the latter may not be diagnostic and repeat scans or further imaging may be necessary. Blood culture

1 Reddy DJ, Ernst CB. Infected aortic aneurysms: recognition and management. Semin Vasc Surg 1988;1:174-81.

Anon. Salmonella infections, England and Wales: reports to the PHLS. CDR Weekly 1998;8(7):58.

3 Lester A, Erikson NHR, Nielson H, et al. Non-typhoid salmonella bacteraemia in Greater Copenhagen 1984-1988. Eur F Microbiol Infect Dis 1991;10:486-90.

4 Mandal BK, Lyons M. Bacteraemia in salmonellosis: a 15 year retrospective study from a regional infectious disease unit. BMF 1988;297:242-3.

5 Parsons R, Gregory J, Palmer DL. Salmonella infections of the abdominal aorta. Rev Infect Dis 1983;5:227-31.

\section{Learning points}

- patients with known or suspected atheromatous disease of the aorta are at increased risk of bacterial aortitis

- Salmonellae are the commonest cause of bacterial aortitis and consideration should be given to antimicrobial therapy for gastroenteritis in at-risk patients

- patients taking gastric acid suppressing drugs are at increased risk of Salmonella infection

- bacterial aortitis is difficult to diagnose and a high index of suspicion is therefore important

- the most useful investigation is CT, but this may be negative

- the most appropriate management is aortic repair combined with antimicrobial therapy

is positive in three-quarters of all cases of Salmonella aortitis. ${ }^{67}$ Optimum treatment requires early surgical intervention and an extended course of appropriate antimicrobial therapy, ciprofloxacin being the drug of choice for Salmonella infections. ${ }^{6-9}$

The diagnosis of Salmonella aortitis in our patient was based on a recent history of Salmonella enteritis in a patient with a pyrexial illness and a leaking aortic aneurysm. The diagnosis was confirmed by the finding of Gram-negative bacilli in the wall of the aorta and it is probable that blood and aortic wall cultures were negative because of the presence of antibiotics in these specimens. Treatment with omeprazole reduces gastric acidity and thereby increases the risk of Salmonella infection. ${ }^{10}$ In addition, this patient was known to have atherosclerotic disease of the aorta and was therefore at increased risk of bacterial aortitis. ${ }^{5}$ We believe that general practitioners and hospital physicians should have a low threshold for prescribing antimicrobial therapy for the treatment of gastroenteritis in patients likely to have atheromatous disease of the aorta.

Even with modern surgical and antimicrobial management, the mortality of Salmonella aortitis exceeds $40 \% .{ }^{67}$ This case demonstrates that in patients with an aortic aneurysm and pyrexial illness of unknown cause, bacterial aortitis should be quickly excluded.

6 Oskoui R, Davis WA, Gomes MN. Salmonella aortitis. Arch Intern Med 1993;153:517-25.

7 Katz SG, Andros G, Kohl RD. Salmonella infections of the abdominal aorta. Surg Gynaecol Obstet 1992;175:102-6.

8 Jagjivan B, Nakielny RA. Case report: salmonella aortitis and aneurysm formation: the role of CT in management. Clin Radiol 1990;40:55-6.

9 Anon. British National Formulary. 1998;35:234.

10 Neal KR, Brij SO, Logan RFA, Hawkey CJ, Slack RCB. Recent treatment with $\mathrm{H}_{2}$ antagonists and antibiotics and gastric surgery as risk factors for salmonella infection. BMF 1994;308:176. 


\title{
A lesson in the management of testicular cancer in a patient with a solitary testis
}

\author{
E J Sawyer, R T D Oliver, J S Tobias, D F Badenoch
}

\begin{abstract}
Summary
Five per cent of patients with germ cell tumours of the testis will develop a further tumour in the contralateral testis. Standard treatment in such cases is a second orchidectomy, resulting in infertility, hormone replacement, and psychological morbidity. In this case report we explore the role of testis conservation in these patients and also show that there is a risk of removing a potentially normal testis if a histological diagnosis is not sought prior to orchidectomy.
\end{abstract}

Keywords: testicular germ cell tumours; carcinoma-insitu; orchidectomy

With the current preference for orchidectomy in patients with suspicious testicular masses there is the risk of removing a potentially normal testis. Experience of a patient with a suspicious mass in a solitary testis which was subsequently found to have benign histology after testis-conserving surgery, prompted us to report the present case.

\section{Case history}

A 39-year-old man presented with a 6-week history of pain in the left groin and suprapubic area with increasing tenderness in the right testis. Fourteen years earlier he had undergone a left orchidectomy and chemotherapy (four cycles of bleomycin, etoposide and cisplatin) for stage 2C teratoma. Since that time he had

Meyerstein Institute of Oncology, The

Middlesex Hospital, London W1N 8AA, UK

E J Sawyer

J S Tobias

St Bartholomew's Hospital, London EC1A 7BE, UK

Department of

Medical Oncology

R T D Oliver

Department of

Urology

D F Badenoch

Correspondence to Dr EJ Sawyer, Molecular and Population Genetics Laboratory, Imperial Cancer Research Fund, 44, Lincolns Inn Fields, London WC2A 3PX, UK

Accepted 14 January 1999 sound using a $7.5 \mathrm{mH}$ ultrasound probe was used to identify the lesion (figure 1), which was though he was aware that the most likely possible to pursue testis conservation. $\mathrm{He}$ underwent exploration of the right testis through a groin incision. Intra-operative ultra-

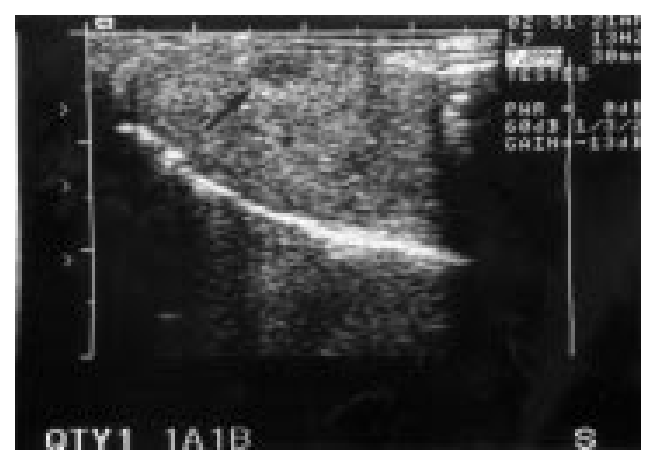

Figure 1 Intra-operative ultrasound revealing a 4-mm hypoechogenic nodule lying immediately on the surface of the exposed testis. The site was marked for excision

excised with a rim of surrounding normal tissue. A separate testicular biopsy was also performed. Despite the clinical prediction of a new primary malignancy, histology of the nodule revealed seminiferous tubules lined only by Sertoli cells and marked proliferation and hyperplasia of Leydig cells. The separate biopsy showed atrophic testis.

\section{Discussion}

This case highlights the problems of diagnosis of testicular masses. Ultrasound is the mainstay for imaging of the testis and has a sensitivity of $80-98 \% .^{1}$ One of its limitations is that non-neoplastic lesions may mimic tumours. Magnetic resonance imaging (MRI) has no proven diagnostic benefit over ultrasound, but provides better localisation when partial orchidectomy is being considered (figure 2 ). ${ }^{2}$ If this surgical approach is followed, then intraoperative ultrasound can be used, as in this case, to delimit the lesion and thus remove as little of the normal testis as possible.

Fine needle aspiration of a suspicious mass is not performed to confirm the diagnosis prior to surgery due to the theoretical risk of tracking at the needle site and scrotal recurrence, although how real this risk is with modern adujvant treatment is unknown. Semen cytology has proved useful but is positive in only $50 \%$ of cases. $^{3}$

Radical orchidectomy rather than partial orchidectomy via an inguinal approach is the operation of choice, as $90 \%$ of testicular germ cell tumours have associated carcinoma in situ (CIS) which progresses to invasive disease in $50 \%$ of cases within 5 years. ${ }^{3}$ Partial orchid- 
Figure 2 Pre-operative MRI scan showing the position of the nodule near the surface of the testis

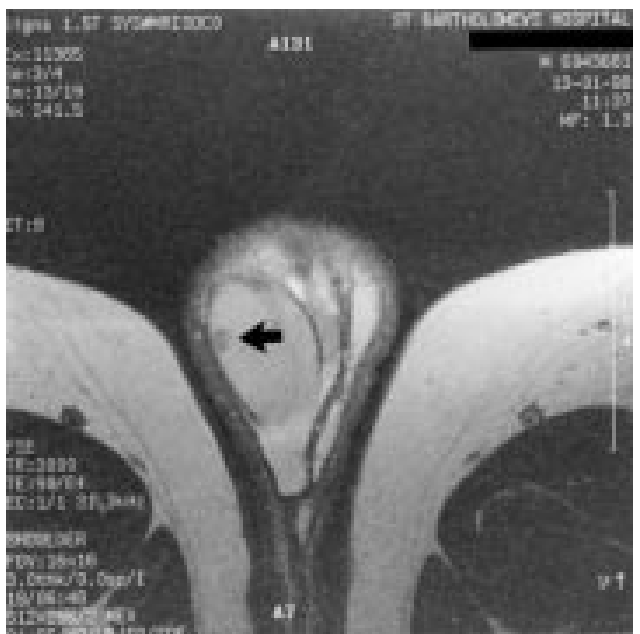

\section{Learning points}

- a histological diagnosis should be made prior to orchidectomy, especially in patients with a solitary testis

- $90 \%$ of testicular germ cell tumours have associated CIS, which progresses to invasive disease in $50 \%$ of cases within 5 years

- biopsy of the contralateral testis is often performed at the time of diagnosis to look for CIS as $5 \%$ of patients will develop bilateral testicular germ cell tumours

- CIS can be treated with radiotherapy, which leads to infertilty but avoids testosterone replacement. If the patient wishes to preserve fertility, chemotherapy can be used with careful observation

- partial orchidectomy followed by radiotherapy or chemotherapy to treat surrounding CIS, can be used as an alternative to orchidectomy

ectomy has been used in benign testicular tumours and has also been described in patients developing a germ cell tumour in a solitary testis. ${ }^{45}$

The issue of disease in a solitary testis is important as $5 \%$ of patients with germ cell tumours of the testis will develop a further tumour in the contralateral testis. ${ }^{6}$ If radical orchidectomy is the treatment of choice then all patients developing bilateral disease will suffer infertility and be committed to life-long testosterone replacement, as well as suffer the psychological burden of bilateral orchidectomy. At present none of the existing treatment modalities for life-long androgen replacement ensure constant physiological testosterone levels, and patients can suffer from disturbances in their libido and sexual dysfunction. ${ }^{7}$

Due to the risk of malignancy in the contralateral testis it is becoming routine in certain centres to biopsy the contralateral testis in patients who present with germ cell tumours looking for CIS. ${ }^{67}$ Radiotherapy has been used successfully to eradicate CIS. Doses of 16 20 Gy in $8-10$ fractions have been given and result in infertility but allow the patient to retain some Leydig cell function, and often avoid testosterone replacement. ${ }^{78}$ For those patients remaining fertile after unilateral orchidectomy who have contralateral CIS and wish to father a family, chemotherapy may be an option. Chemotherapy has not produced $100 \%$ durable suppression of CIS and such patients will require careful observation as the disease may recur in up to $50 \%$.

In patients with a tumour in a solitary testis, the above techniques can be applied following partial orchidectomy, ie, partial orchidectomy is used to remove the tumour and then followed by radiotherapy to the testis or chemotherapy in order to eradicate or control CIS. $^{8}$ Another option in these patients is chemotherapy alone. Evidence for this has come from a series of 32 patients who presented with metastatic disease and received chemotherapy without undergoing orchidectomy. Fourteen of these patients had no residual disease in their testis after treatment, while 13 remained relapse-free for a median of 7 years, although there was one relapse at 12 years. ${ }^{9}$

The advantages of using partial orchidectomy are well illustrated in this case as it allows a histological diagnosis to be made and a treatment plan formulated depending on the patient's wishes, particularly when considering issues of fertility and hormone replacement. It is especially important to consider these concerns in patient with a solitary testis but the same principles should be applied to all patients, as there are minor complications and psychological morbidity associated with orchidectomy.

A theoretical disadvantage is that partial orchidectomy and associated postoperative haematoma may distort the anatomy and make follow-up difficult. Although data on this are limited, experience of follow-up in four patients by one of us (RTDO) has not been a problem provided findings from ultrasound and clinical examination are taken together. Three of these patients have also had MRI, which adds little, although it improves the ease of getting a three-dimensional perspective of the testis.

Our patient was found to have Leydig cell hyperplasia, a benign condition requiring no further treatment following excision. It has been reported in patients with testicular tumours secreting high levels of $\beta$-hCG. There is a single case report of Leydig cell hyperplasia mimicking a testicular tumour in a patient treated 21 years previously for an extragonadal seminoma. ${ }^{10}$ In this case the patient underwent orchidectomy for a benign condition.

In summary, ultrasound is not a foolproof method of diagnosing testicular tumours and if unnecessary orchidectomy for benign disease is to be avoided, an attempt at histological diagnosis must be made. At present this is best done by partial orchidectomy. If malignancy is confirmed then radical orchidectomy is not mandatory and radiotherapy or chemotherapy as discussed above should be considered. 
1 London NJ, Smart JG, Kinder RB, Watkin EM, Rees Y, Haley P. Prospective study of routine scrotal ultrasonograHaley P. Prospective study of routine scrotal ultras
phy in urological practice. Br f Urol 1989;63:416-9.

2 Walker BR, Skoog SJ, Winslow BH, Canning DA, Tank ES Testis sparing surgery for steroid unresponsive testicular tumours of the adrenogenital syndrome. F Urol 1997;157: $1460-3$

3 Oliver RTD. Results and late effects of treatment for early stage germ cell tumours. In: Tobias JS, Thomas PRM, eds. Current radiation oncology, Vol 2. London: Arnold, 1996; pp 390-416.

4 Sobeh MS, Jenkins BJ, Paris AMI, Oliver RTD. Partial orchidectomy for testicular tumour. Eur F Surg Oncol 1994; 20:585-6.

$5 \mathrm{Ng} \mathrm{RSH}$. The reproductive imperative: a case report highlighting the possibility of using chemotherapy to conserve the testis in patients with testis cancer. Clin Oncol 1997;9:334-7.
6 Loy V, Dieckmann KP. Prevalence of contralateral testicular intraepithelial neoplasia in patients with testicular germ cell tumour. Eur Urol 1993;23:120-2.

7 Giwercman A, Maase H von der, Rorth M, Skakkebaek NE Current concepts of radiation treatment of carcinoma in situ of the testis. World f Urol 1994;12:125-30.

8 Dieckmann KP , Loy V. Management of contralateral testicular intraepithelial neoplasia in patients with testicular germ cell tumour. World 7 Urol 1994;12:131-5.

9 Oliver RTD, Ong J, Blandy JP, Altman DG. Testis conservation studies in germ cell cancer justified by improved primary chemotherapy response and reduced delay, 19781994. Br F Urol 1996;78:119-24.

10 Olumi AF, Garnick MB, Renshaw AA, Benson CA, Richie JP. Leydig cell hyperplasia mimicking testicular neoplasm. Urology 1996;48:647-9.

\title{
Extramedullary myeloid cell tumour: presentation as anterior chest wall mass during AML relapse
}

\author{
Jyoti Wadhwa, S Gujral, Lalit Kumar, B K Mohanti, Vinod Kochupillai
}

\begin{abstract}
Summary
Acute myeloid leukaemia is an uncommon but an important cause of soft tissue swellings. Such extrameningeal, extramedullary leukaemic infiltrates are called extramedullary myeloid cell tumours. Despite their large size they may respond well to chemotherapy and local radiotherapy, as is demonstrated in this case.
\end{abstract}

Keywords: myeloid cell tumour; acute myeloid leukaemia

Extramedullary myeloid cell tumour (EMT), also known as granulocytic sarcoma, is known to occur in $3-7 \%$ of patients with acute myeloid leukemia (AML). ${ }^{12}$ It can occur at initial presentation or at relapse. We report a case of AML in relapse presenting with a large anterior chest wall mass which was confirmed to be EMT and which responded completely to a combination of chemotherapy and radiotherapy.

\section{Case report}

A 49-year-old man was diagnosed as a case of AML-M1 in May 1996. He failed to achieve remission after induction chemotherapy with idarubicin and cytosine arabinoside. Complete remission was achieved after re-induction chemotherapy with daunorubicin and cytarabine given for 3 and 7 days, respectively, in the standard dosages. He subsequently completed consolidation chemotherapy (total of three cycles). The first and third cycle of consolidation therapy were similar to the re-induction chemotherapy regimen. The second cycle consisted of intermediate dose cytosar $\left(1 \mathrm{~g} / \mathrm{m}^{2}\right.$ bid for 5 days). He subsequently received alphainterferon as part of research protocol to study the efficacy of alpha-interferon during consolidation and maintenance. While on interferon therapy, he presented in November 1997, with a progressively increasing painless lump over the anterior chest wall in the midline, of 3 weeks duration. Examination revealed a performance status of I (ECOG), and a hard mass measuring $10 \times 14 \mathrm{~cm}$ overlying the anterior chest wall (figure 1). It was fixed, non-tender and non-pulsatile with bluish discolouration of overlying skin. Hepatomegaly $(3 \mathrm{~cm})$ below the right costal margin and splenomegaly $(4 \mathrm{~cm})$ below the left costal margin were also noted.

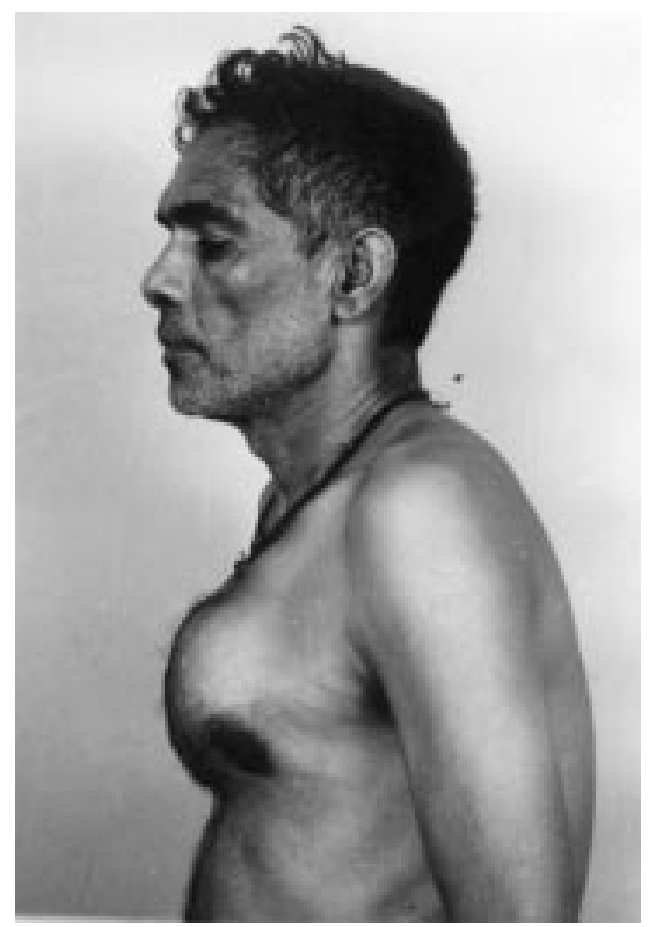

Figure 1 Lateral view showing a large mass over the anterior chest wall (reproduced with the patient's permission) 
Figure 2 FNAC of the chest wall mass

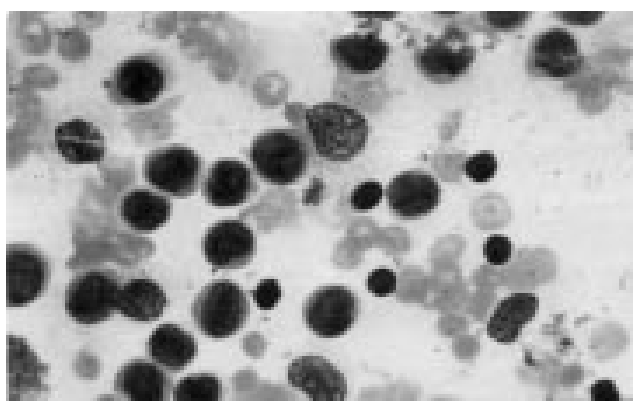

Investigations revealed haemoglobin $12 \mathrm{~g} / \mathrm{dl}$, total leucocyte count $26 \times 10^{9} / 1$ and platelet count $338 \times 10^{9} / 1$. Peripheral smear revealed $40 \%$ blasts, $2 \%$ myelocytes, $20 \%$ neutrophils and $38 \%$ lymphocytes. Fine needle aspiration cytology (FNAC) of the chest wall mass revealed a cellular smear showing haemopoietic cells including $18 \%$ blasts, $6 \%$ myelocytes, $29 \%$ neutrophils, $12 \%$ monocytes, and $35 \%$ lymphocytes (figure 2), confirming the diagnosis of EMT. On cytochemistry, blasts were positive for myeloperoxidase. Immunocytochemistry (APAAP) revealed the blasts to be positive for CD34, CD13 and CD33 and negative for other $\mathrm{T}$ and $\mathrm{B}$ cell markers. $\mathrm{X}$-Rays of sternum and the bone scan were normal. Thus, a diagnosis of AML with relapse and EMT of the anterior chest wall, was made.

The patient received chemotherapy including daunorubicin and cytarabine for 3 and 7 days, respectively. He also received local radiotherapy to the mass using $12 \mathrm{Mev}$ electrons (dose $=8 \mathrm{~Gy} /$ single fraction). Following this therapy, he achieved complete remission and the chest wall mass disappeared, leaving behind only the skin discolouration. The patient has now completed consolidation chemotherapy using high-dose cytosar, and was doing well on maintenance therapy with cytarabine and 6-mercaptopurine at last follow-up in September 1998 .

\section{Discussion}

The term EMT refers to a solid tumour of any organ recognisable microscopically as a sarcoma, composed of leukaemic cells of the myeloid series. The term EMT encompasses all terms of extrameningeal, non-medullary
1 Nieman RS, Barcos M, Berard C, et al. Granulocytic sarcoma: a clinicopathologic study of 61 biopsied cases. Cancer 1981;48:1426-37.

2 Byrd JC, Edenfield WJ, Dow NS, Aylesworth C, Dawson N. Extramedullary myeloid cell tumor in myelodysplastic syndrome: not a true indication of impending acute myeloid leukemia. Leuk-lymphoma 1996;21:153-9

3 Liu P1, Ishimaru T, McGregor DH, Okada H, Steer A. Autopsy study of granulocytic sarcoma (chloroma) in patients with myelogenous leukemia, Hiroshima Nagasaki 1949-1965. Cancer 1975;31:948-55. leukaemic infiltrates. ${ }^{2}$ Skin is one of the commonest sites of involvement. An autopsy study revealed that observable tumour nodules were most frequent in the orbit and in the chest wall. ${ }^{3}$ EMT may appear as an isolated disease, during the course of the illness, or may antedate it by a few days to months. In this patient soft tissue swelling diagnosed as EMT developed during the course of illness. This patient presented with EMT of skin of anterior chest wall and was also found to be in medullary relapse. Underlying bony involvement (of sternum/ribs) was excluded by a normal bone scan.

Acute monocytic and myelomonocytic leukaemias have a higher frequency of overt infiltrative tissue lesions than other forms of AML. Previous studies have shown that EMT is most commonly associated with AML-M4. ${ }^{2}$ This patient had been diagnosed as AML-M1 and later progressed to develop EMT.

The present case report highlights certain important findings. Meticulous FNAC of the swelling should be an essential component of the initial diagnostic work-up of patients with haematological malignancy who develop soft tissue swelling. FNAC smears stained with Jenner-Giemsa (Romanowsky stain) give a diagnostic picture showing the presence of myeloid and erythroid precursors, azurophilic granules, and Auer rods, making the diagnosis quick and easy. Therefore, for the diagnosis of EMT, morphological examination of a JennerGiemsa stained FNAC smear is a must and may be accompanied by cytochemical (MPO, NSE) and immunocytochemical (CD13, CD14, CD33, CD43, anti-MPO) stains, as done in our case.

Patients who present with EMT at AML relapse have always been treated with systemic re-induction chemotherapy. The tumour response to local external radiotherapy in combination with chemotherapy has been well documented. ${ }^{4-6}$ This patient also showed complete response to chemotherapy with daunorubicin and cytosine arabinoside and local electron beam therapy. He achieved haematological remission and there is no evidence of local tumour. Prognosis for patients with EMT is related to the course of the underlying disease process. Survival in such patients has been reported to range from one to 30 months after the onset of EMT. ${ }^{3}$
4 Washburn AH, Dittes WL. Chloroma vs granuloma. Am $\mathcal{F}$ Dis Child 1962;104:126.

5 Comings DE, Fayer AW, Carter P. Myeloblastoma preceding blood and marrow evidence of acute leukemia. Cancer 1965;18:253.

6 Wiernik PH, Serpick AA. Granulocytic sarcoma (chloroma). Blood 1970;35:361-9. 


\title{
Hereditary hypophosphataemic rickets: report of a family from the Indian subcontinent
}

\author{
Abdul Hamid Zargar, Bashir Ahmad Laway, Shariq Rashid Masoodi, \\ Fayaz Ahmad Hakim, Arshad Iqbal Wani, Mir Iftikhar Bashir, Ambrish Mithal
}

\begin{abstract}
Summary
Nutritional deficiency continues to be an important cause of rickets in the underdeveloped and developing parts of the world. In the western hemisphere, predominantly non-nutritional forms of rickets and osteomalacia are now seen. In this report we discuss a family with $\mathrm{X}$-linked hypophosphataemic rickets from the Kashmir region of the Indian subcontinent (which is an uncommon entity here).
\end{abstract}

Keywords: hypophosphataemia; rickets

Nutritional deficiency is no longer an important cause of rickets in the western world, although it still is in India. ${ }^{1}$ Rickets and osteomalacia can occur in association with a variety of disorders of proximal renal tubular function; these disorders have in common increased renal clearance of inorganic phosphates and hypophosphataemia with a normal glomerular filtration rate. Primary hypophosphataemic rickets is characterised by severe short stature and rickets in association with hypophosphataemia and hyperphosphaturia and usually has an X-linked mode of inheritance. ${ }^{2}$ In this report we describe a family with hypophosphataemic rickets where we believe the mode of transmission is X-linked dominant. A Medline search for the last 30 years revealed only one such family described from India so far. ${ }^{3}$

\section{Case report}

Index case

A 3-year-old girl, 5th in birth order was born of a full term normal delivery at home. She had failed to thrive since the age of 2 years. There was no suggestion of any chronic systemic disease. Examination revealed a well-nourished girl, height $79 \mathrm{~cm}$, weight $10 \mathrm{~kg}$ (expected 50th percentiles for her height and weight: $94 \mathrm{~cm}$ and $10.5 \mathrm{~kg}$, respectively). Upper segment lower segment ratio was 1.23. She had frontal bossing, widening of epiphyseal ends of long bones with knock knees, rachitic rosary, Harrison's sulcus and pigeon chest deformity. Family history was significant (figures 1 and 2). Of her four siblings, the three males (E-G) were normal while the other girl (B) was affected. Her father (C ) and paternal uncle (D) were affected while her mother was normal. Her paternal grandmother, who had died 10 years earlier, was also reported to have had short stature and leg deformities.

\section{Other affected cases}

Elder sister (B): Although she had a chronological age of 16 years, there had also been a failure of linear growth since the age of 3 years, and she had gradually developed deformities of the lower limbs. She had attained menarche at age 14 years and was having regular cycles. Examination revealed a height of $134 \mathrm{~cm}$ and weight of $35 \mathrm{~kg}$ (expected 50th percentiles were $157 \mathrm{~cm}$ and $47.5 \mathrm{~kg}$, respectively). She had mild pallor, knock knees, mild anterior bowing of legs, widening of epiphyses and pigeon chest deformity. Systemic examination was normal.

Father (C): Aged 48 years, he had developed progressive deformity of upper and lower limbs during his childhood. He was $140 \mathrm{~cm}$ tall (corresponding to a height age of 11 years) and weighed $42 \mathrm{~kg}$ (consistent with his present height). He had multiple bony deformities including bowing of legs, bending of forearms, lumbar kyphoscoliosis. Systemic examination was normal.

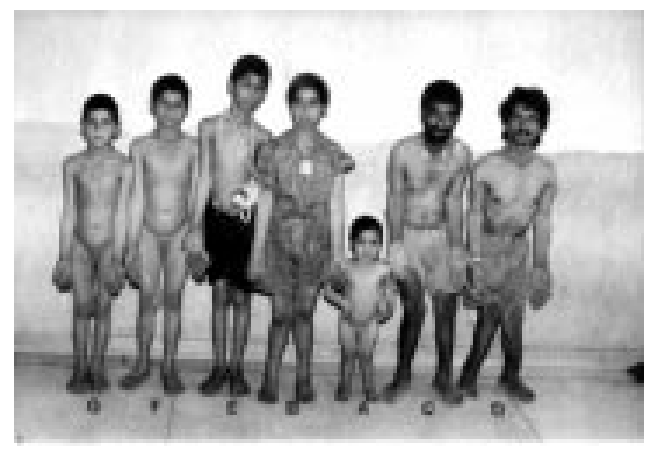

Figure 1 Family photograph showing short stature and anterior bowing of legs in affected individuals (reproduced with their permission)

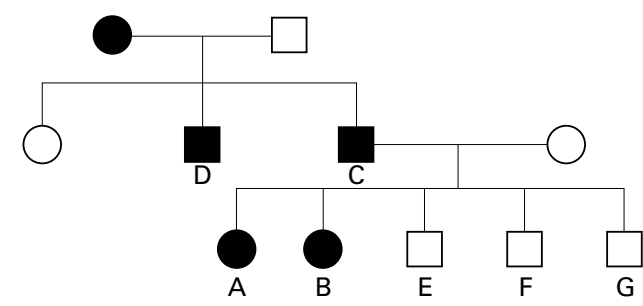

Figure 2 Family pedigree, identifying individuals affected 


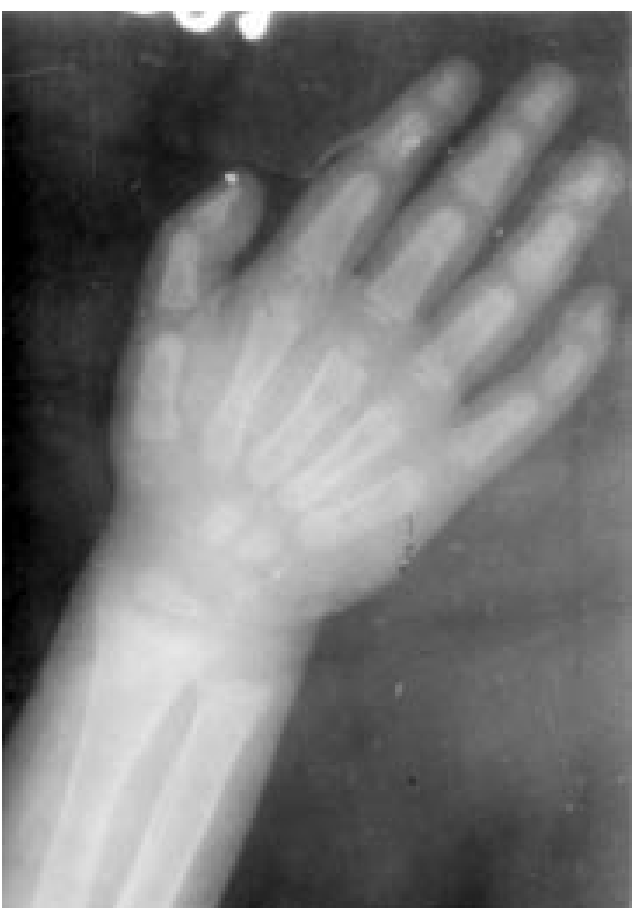

Figure 3 X-ray of the wrist showing changes of rickets at the epiphysial end of long bones

Paternal uncle (D): Aged 35 years, he was 137 $\mathrm{cm}$ tall, consistent with a height age of 10 years. He weighed $38 \mathrm{~kg}$. He had knock knees, anterior bowing of both legs and lumbar scoliosis.

Full blood count, serum and urinary calcium, and ammonium chloride test were normal in all subjects, and none of them had proteinuria or glycosuria. Radiological screening revealed advanced changes of rickets/osteomalacia in the affected subjects (figures 3 and 4). There was a mild elevation of total alkaline phosphatase in the affected subjects, all of whom had persistent hypophosphataemia. Mean serum phosphorous was $1.9 \mathrm{mg} / \mathrm{dl}$ in affected members and $4.5 \mathrm{mg} / \mathrm{dl}$ in unaffected ones (normal range, $3.0-4.5 \mathrm{mg} / \mathrm{dl}$ ). Our index case, surprisingly, had high serum 25hydroxyvitamin $\mathrm{D}(>100 \mathrm{ng} / \mathrm{ml})$ and undetectable $(<5 \mathrm{pg} / \mathrm{ml})$ 1,25-dihydroxyvitamin $\mathrm{D}$. This biochemical abnormality was reproducible. Serum levels of 25-hydroxyvitamin D and 1,25-dihydroxyvitamin D were normal in other affected as well as unaffected subjects (table).

Table Biochemical investigations

\begin{tabular}{|c|c|c|c|c|c|c|}
\hline Subject & $\begin{array}{l}\text { Serum Ca } \\
(\mathrm{mg} / \mathrm{dl})\end{array}$ & $\begin{array}{l}\text { Serum P } \\
(m g / d l)\end{array}$ & $\begin{array}{l}\text { Serum } A L P \\
(U / l)\end{array}$ & $\begin{array}{l}\text { Urinary Ca } \\
\text { (mg/day) }\end{array}$ & $\begin{array}{l}\text { Serum } \\
25(\mathrm{OH}) D \\
(\mathrm{ng} / \mathrm{ml})\end{array}$ & $\begin{array}{l}\text { Serum } \\
1,25(\mathrm{OH})_{2} D \\
(\mathrm{pg} / \mathrm{ml})\end{array}$ \\
\hline A & 9.6 & 1.9 & 721 & 194.6 & $>100$ & $<5.0$ \\
\hline B & 9.01 & 2.1 & 587 & 205.7 & 9.4 & 18.0 \\
\hline C & 8.23 & 1.6 & 373 & 118.4 & 28.0 & 19.0 \\
\hline D & 8.8 & 2.3 & 721 & 110.2 & 32.0 & 17.0 \\
\hline E & 9.36 & 4.5 & 371 & 214.2 & 36.2 & 14.0 \\
\hline F & 8.15 & 4.2 & 347 & 197.3 & 39.0 & 31.0 \\
\hline G & 8.30 & 4.1 & 307 & 227.2 & 25.7 & 26.0 \\
\hline $\begin{array}{r}\text { Normal } \\
\text { range }\end{array}$ & $9-10.5$ & $3-4.5$ & $30-120$ & $100-400$ & $8-80$ & $16-65$ \\
\hline
\end{tabular}

ALP: alkaline phosphatase

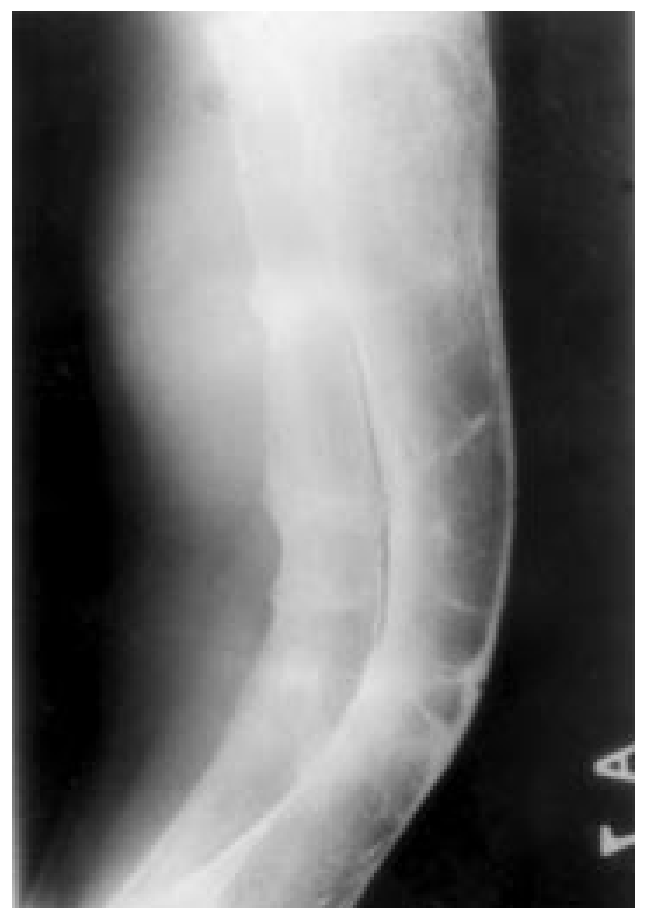

Figure 4 X-ray of the lower limbs showing bowing of long bones with multiple previous fractures

\section{Discussion}

In India, malnutrition continues to be the leading cause of rickets, although other causes of rickets are increasingly recognised. ${ }^{4}$ In this study we describe a family in which all the female children had advanced changes of rickets/osteomalacia while the male children were spared. Their father and paternal uncle were affected while their mother was normal. Historically, their paternal grandmother had also been affected. Thus, it is evident that transmission of the disease is X-linked dominant.

In developed nations nutritional rickets, primarily due to vitamin $\mathrm{D}$ deficiency, has almost been eliminated as a result of fortification of some foods. By the 1940s vitamin D deficiency was no longer considered to be an important cause of osteomalacia and rickets. In North America the most common form of inherited rickets is X-linked dominant hypophosphataemic rickets. ${ }^{5}$ This entity was first described by Albright and co-workers in $1937 .{ }^{6}$ The phenotypic trait of hypophosphataemia is transmitted on the X-chromosome. Patients with familial hypophosphataemic rickets are recognised by marked rickets with hypophosphataemia and hyperphosphaturia coupled with increased serum alkaline phosphatase with normal or slightly reduced serum calcium; urinary phosphate excretion is high, despite hypophosphataemia indicating a defect in renal tubular reabsorption of phosphate. Phosphaturia is unassociated with either aminoaciduria, glucosuria, bicarbonaturia, or kaliuria. ${ }^{7}$ Serum levels of immunoreactive parathyroid hormone are either normal or mildly increased. ${ }^{8}$ Serum levels of 25-hydroxyvitamin D are normal whereas 
1,25-dihydroxyvitamin D levels are either normal or low. ${ }^{910}$ Our index case had elevated 25-hydroxyvitamin D levels with undetectable 1,25-dihydroxyvitamin D. The only logical explanation for this biochemical abnormality could be a concomitant sporadic $1 \alpha$ hydroxylase deficiency.

Children affected with this disorder progressively develop lower limb deformities once they begin to walk and bear weight. The deformities progressively worsen in an otherwise wellnourished and healthy child. The rate of linear growth is at first normal and then slowed, ultimately resulting in short stature. ${ }^{2}$

On the basis of restriction fragment polymorphism studies in several kindred of $\mathrm{X}$-linked hypophosphataemia, the mutant gene has been mapped to the short arm of the $\mathrm{X}$-chromosome (Xp22.1). A candidate gene called PEx that exhibits homology to a family of endopeptidase genes has been identified and several mutations, including deletions, frame shifts and splice-junction defects, have been reported. $^{10}$

1 Goldring SR, Krkane SM, Avioli LV. Disorders of calcification: osteomalacia and rickets. In: DeGroot LJ, ed, Endocrinology,

2 Chesney RW, Novello AC. Defects of renal tubular transport. In: Massry SG, Glassock RJ, eds. Textbook of nephrology, 3rd edn. Baltimore: Williams and Wilkins, 1995; pp 513-29.

3 Pathak KJ, Lakhani JD, Modi KR, Patel PM. Familial $\mathrm{X}$-linked dominant hypophosphatemic vitamin D refractory rickets - a family study. $\mathcal{F}$ Assoc Phys India 1982;30:323-5.

4 Zargar AH, Laway BA, Masoodi SR, Wani AI. An aetiological profile of short stature in the Indian subcontinent. $f$ Pediatr Child Health 1998;34:571-6.

5 Rasmussen H, Tenenhouse HS. Hypophosphatemia. In: Scriver CR, Beandet AL, Sly WS, Valle D, eds. The metabolic basis of inherited diseases. New York: McGraw-Hill, 1989; pp 2581-604.

6 Albright F, Butler AM, Bloomberg E. Rickets resistant to vitamin D therapy. $\mathcal{F}$ Clinic Dis Child 1937;54:529-47.

7 Cjesney RW. Metabolic bone disease. In: Nelson WE, ed Textbook of pediatrics, 15th edn. Banglore, India: Prism Textbook of pediatrics, 15th edn.

\section{Learning points}

- hypophosphataemia is an uncommon cause of rickets in India

- subjects show changes characteristic of deforming rickets with severe compromise of height

- hyperphosphaturia is present despite hypophosphataemia

- combination of oral phosphate and 1,25-dihydroxyvitamin D3 significantly improves the clinical course of disease in children

Treatment of this disorder continues to be a therapeutic challenge. Administration of 1,25dihydroxyvitamin D and phosphates significantly improves the clinical course of this disease in childhood. ${ }^{11}$ A similar therapeutic regimen results in significant clinical and histomorphometric improvement in adults with this disorder. ${ }^{12}$

8 Delvin EE, Glorieux FH. Serum 1,25-dihydroxy vitamin D concentration in hypophosphatemic vitamin D-resistant rickets. Calcif Tissue Int 1981;33:173-5.

9 Lyles KW, Drezner MK. Parathyroid hormone effect on serum 1,25-dihydroxy vitamin D levels in patients with $\mathrm{X}$-linked hypophosphatemic rickets: evidence for abnormal 25-hydroxy vitamin D1-hydroxylase activity. $\mathcal{F}$ Clin Endocrinol Metab 1982;54:638-44.

10 Krane SM, Holick MF. Metabolic bone disease In: Fauci AS, ed. Harrison's Principles of internal medicine, 14th edn. New York: McGraw Hill, 1998; pp 2247-59.

11 Glorleux FH. Calcitriol treatment in vitamin D-dependent and vitamin D-resistant rickets. Metabolism 1990;39(suppl 1): $10-2$.

12 Sullivan W, Carpenter T, Glorieux F, Traver SR, Insogna K. A prospective trial of phosphate and 1,25-dihydroxy vitamin D3 therapy in symptomatic adults with X-linked hypophosphatemic rickets. $\mathcal{F}$ Clin Endocrinol Metab 1992;75:879-85. 